\title{
Design and analysis of double stator HE-FSM for aircraft applications
}

\author{
Hassan Ali ${ }^{1}$, Erwan Sulaiman², Mahyuzie Jenal' ${ }^{3}$, Irfan Ali ${ }^{4}$, Laili Iwani Jusoh ${ }^{5}$, Zarafi Ahmad ${ }^{6}$, \\ Mohd Firdaus ${ }^{7}$ \\ 1,2,3,4,5,6Research Centre for Applied Electromagnetics, Universiti Tun Hussein Onn Malaysia, Batu Pahat, Malaysia \\ ${ }^{7}$ Center for Roboticts \& Industrial Automation, Fakulti Kejuruteraan Elektrik, University Teknikal Malaysia Melaka, \\ urian Tunggal, Malaysia
}

\section{Article Info}

Article history:

Received Aug 26, 2020

Revised Jan 14, 2021

Accepted Jan 26, 2021

\section{Keywords:}

Aircraft

Double stator

Flux switching

Hybrid excitation

Segmented rotor

\begin{abstract}
The main objective of aerospace industry is to produce all electric aircraft (AEA) equipped by electrical devices in coming developments. Electrical machines that provide higher torque densities are gaining more interest for researchers to obtain sustainable direct-drive electrical propulsion system for aircraft applications. In addition to lesser weight and higher torque density, a machine should be "fault tolerant" to applied in aerospace applications. A novel machine for high starting torque, identified as flux switching machine (FSM) was established over the last decade. FSMs comprise all effective sources on stator including robust rotor structure. These machines exhibited higher "torque-to-weight ratios" and reliability. Nonetheless, the challenge of developing a machine suitable for aircraft applications goes far beyond electromagnetic design and much deeper into the field of mechanical systems than traditional ones. Thus, a new double stator (DS) hybrid excitation (HE) FSM design employing segmented rotor is proposed and analyzed in this research work. The suggested design for DS HE-FSM comprises of six field excitation coils (FECs) and six permanent magnets (PMs) as their excitation sources. In this research, investigation of DS HE-FSM is accomplished with respect to flux linkage, back EMF, cogging torque and torque analysis based on 2D FEA.
\end{abstract}

This is an open access article under the CC BY-SA license.

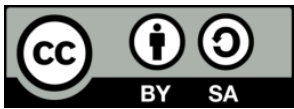

\section{Corresponding Author:}

Hassan Ali

Research Center for Applied Electromagnetics

Institute of Integrated Engineering

Universiti Tun Hussien Onn Malaysia, 86400 Parit Raja, Batu Pahat Johor, Malaysia

Email: engg.hassansoomro@gmail.com

\section{INTRODUCTION}

The Integration of electrical power to drive aircraft systems and sub-systems previously propelled by hydraulic, pneumatic, and mechanical structures is now becoming an attractive segment in the aviation industry. Advancements in the power electronics sectors provide the innovations to improve the effectiveness and protection of operation. The aviation industry operators undergo a long-term transformation from mechanical, hydraulic, and pneumatic power systems to worldwide optimized electrical systems [1]-[3]. Electric motor drives are capable of transferring electrical power to various systems, like drive actuators, pumps, compressors as well as other subsystems at various speeds, combined with progressive electronics and control approaches [4]. Electrical drives are able to offer improvements in overall performance, while reducing weight and meeting reliability requirements at low cost. The main objective for the aviation industry is to accomplish the all-electric aircraft (AEA), converting all power systems to electric power [5]. Moreover, 
mechanically actuators have significantly replaced hydraulic actuators with electronic servo valve control. The "more electric" advancement has permitted decrease in mechanical components and hydraulic power supply systems to be more simplified. Such as, electric machine fuel pumps were recognized in place of hydraulic pumps to offer advantages of system efficiency, and speed control flexibility [6], [7].

Significant improvements can be acquired by presenting multi-phase machines to enhance the reliability of motor drives for MEA. These machines are typically represented as machines with more than three phases, this number being presumed to be the critical threshold in situation of a single-phase fault. Reporting suggestions for multi-phase motors powered by multi-phase electronic converters can be found in literature, in which both the motor and the drive are required to meet extreme fault tolerant requirements [8], [9]. By providing solutions for potential failures, a fault-tolerant system can realize goals of reliability deprived of resorting to un-optimized redundancy or over-sizing [10]. Engine generators, flight surface actuators, flap actuators, engine fuel pumps, and landing gear nose wheel steering systems are main regions to be condsider for safety drives in aircraft [11].

Recently, for top performance applications like within the aerospace, and electric vehicles, "flux switching machines" (FSM) using PMs have presented high torque densities besides "fault tolerance" abilities [12]-[14]. FSMs contain active sources flux within the stationary part of the motor with the benefit of sturdy rotor assembly, which is helpful to be used for higher speed applications. Where the flux control is maintained by DC excitation coil. FSMs are divided three main types such as "permanent magnet (PM) FSM", "field excitation (FE) FSM", and "hybrid excitation (HE) FSM". Active flux producing sources in case of "PMFSM" and "FE-FSM" are PMs and "field excitation (FE) coil" respectively. While in case of "HE-FSM" PMs and FE Coils are combined to generate the flux [15], [16].

"PM-FSMs" are becoming common in different applications due to the technologically advanced high-performance rare earth magnetic products, varying from electric and hybrid electric cars, renewable energy systems like wind power turbines, electric aircraft, industrial drives, automation to household appliances [17], [18].

Moreover, "PM machines" have certain limitations, such as higher cost of "rare earth" materials, comparatively low flux weakening, unchanging flux, demagnetization and restricted operating temperature [19]. Hence, the machines which are completely free from PMs got attention of the researchers. FE-FSM was suggested and evaluated using "double stator" in [20], [21]. Though, this causes high "copper losses", as both the armature and field coils are mounted individually on both stators. Besides, it also compromises the torque and efficiency because of low flux strength [22].

Consequently, the idea of HE machines have been proposed to incorporate the advantages PM and DC excitations. HE machines are effective applicants for varying speeds applications e.g. electric cars, aircraft and wind power generation [23]-[25]. HE machine models are diversified, as two sources of excitation are being assembled efficiently. In the last twenty years a wide variety of promising designs have been studied and developed. Even so, these structures are needed to be further improvement due to flux cancellations issues between certain PM flux and FE flux.

Therefore, the new structure of DS HE-FSM with segmented rotor has been proposed and examined in this paper. PM and FE are being used as main and secondary excitation in the proposed system and generate "parallel hybrid excitation" to prevent "flux cancellations" and the influences of demagnetization. In addition, the coil test is performed to legitimize the motor's operating principles, as well as the non-load and load conditions performance is also observed based on the 2-D FEA.

\section{PARAMETR SPECIFICAIONS AND DESIGN METHODOLOGY OF PROPOSED DS HE-FSM}

The design specification and parameters of a proposed (DS) HE-FSM using segmental rotor are itemized in Table 1. The maximum limit of both "armature current density $\left(J_{a}\right)$ " and "FEC current density $\left(J_{e}\right)$ " is $15 \mathrm{~A} / \mathrm{mm}^{2}$. Whereas, the weight of PM is fixed as $1 \mathrm{~kg}$. The proposed machine consists of 6 PMs situated only at internal stator tips, together with 6 FECs uniformly distributed in the midst of each outer stator teeth. Armature windings and FECs are mounted on the outer stator. Figure 1 presents a cross-sectional view of proposed DS HE-FSM with a segmented rotor. The flux linkage in the armature coil has one periodic cycle for motor rotation through $1 / 10$ of a revolution and so the frequency of back EMF in the armature coil is ten times the mechanical rotation.

The design specifications are basically classified into two parts, including those referring to the stators and the rotor. On the stator, it is subdivided into three clusters which are the shape of the FEC slot, the shape of the armature slot and the PM in (inner stator). 
Table 1. Design parameters and restrictons of DS

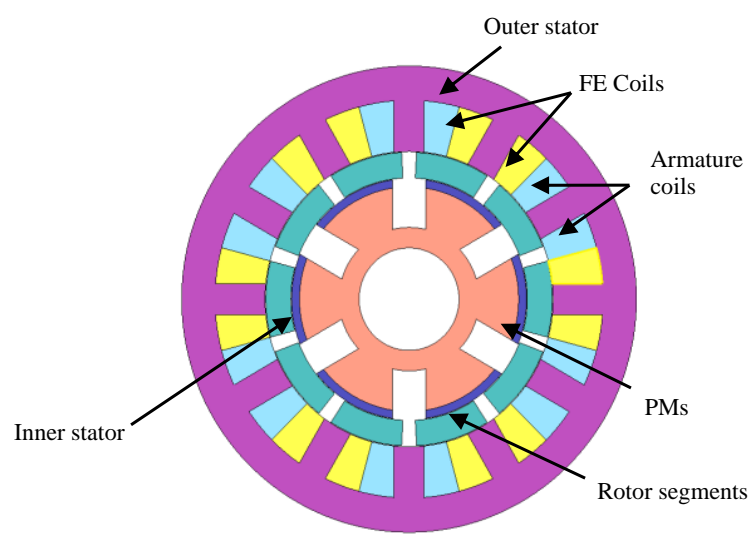

Figure 1. Initial design of proposed DS HE FSM with segmental rotor

\section{PERFORMANCE ANALYSIS OF DS HE FSSM}

Performances of proposed DS HE-FSM are analyzed on the basis of 2D-FEA using JMAG designer. The material used for PM is "NEOMAX-35AH" while "electro-magnetic steel (35H210)" is used for the cores of rotors and stators. The slot area of the "armature coil $\left(S_{a}\right)$ " provides maximum amount of armature coil turns $\left(N_{a}\right)$, while, the boundaries of "armature current density $J_{a}$ " is set to $15 \mathrm{Arms} / \mathrm{mm}^{2}$. Equally, the maximum "field current density $J_{e}$ " is set to $15 \mathrm{~A} / \mathrm{mm}^{2}$.

\subsection{Flux linkage at diffrent sources}

The results of suggested "DS HE-FSM with segmented rotor" at open circuit including flux linkage, back-EMF, and cogging torque are initially evaluated. Flux linkage is an examination to affirm the "magnetic flux", produced through the combination of "PMs and FECs". The flux linkage of proposed machine is investigated and compared at different excitations sources such as PM only, FEC only and at HE conditions as shown in Figure 2. From the figure, it can be seen that the machine draws lowest flux linkage when only FE sources is active (without PMs).

The determined flux linkage is generated as both the excitations are used at hybrid condition where the flux linkage achieved is almost $0.0345 \mathrm{~Wb}$. It also verifies that the flux linkages from both sources are combined properly and hybrid excitation is successfully achieved. Whereas, in case of "only PM excitation", the amount of flux density obtained is approximately $0.025 \mathrm{~Wb}$.

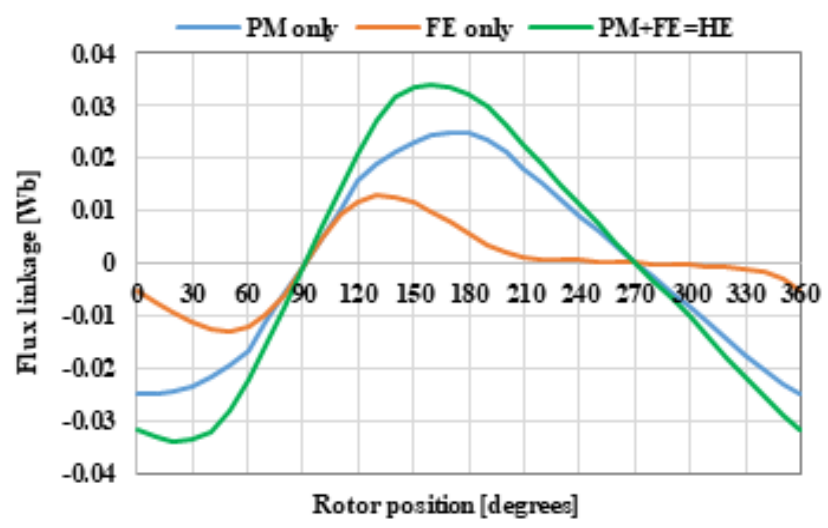

Figure 2. Flux linkage at various conditions PM only, FEC only and HE

\subsection{Cogging torque examination of DE HE-FSM}

At first, the behavior of the cogging torque for presented DS HE-FSM has been evaluated being shown in Figure 3 at no load circumstance. That can be seen from figure that cogging torque at "PM only" is about 5.57 Nm peak to peak. Although the maximum field current density of $15 \mathrm{~A} / \mathrm{mm}^{2}$ is inserted into field 
coil in the case of FE only. In the case of "FE only" the value of cogging torque is increased due to high current in the FE coil, which can cause fluctuations and ambient sounds in the motor.

On the other side, while machine is under no load circumstances, the cogging torque is dropped, and a reasonable value of about $12 \mathrm{Nm}$ "peak to peak" has been generated. Though, the obtained value of "cogging torque" of the initial design is high compared to "in case of PM only". The initial structure of the new "DS HE-FSM" affirms that the performance of proposed motor will be uniform at higher speeds with fewer vibrations and noises.

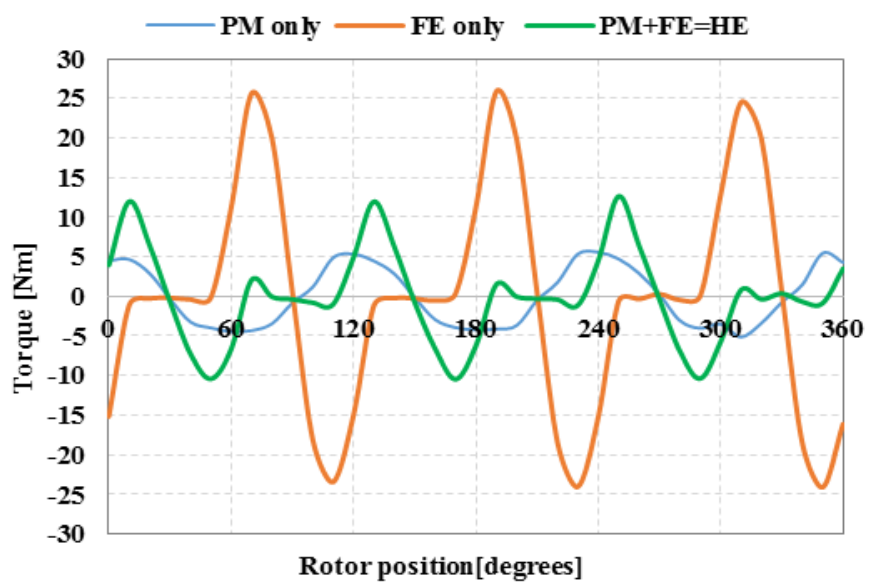

Figure 3. Cogging torque of proposed DS HE FSM with segmental rotor

\subsection{Induced EMF of proposed DS HE-FSM}

Figure 4 demonstrate induced EMF of suggested DS HE-FSM at open circuit condition with speed of $500 \mathrm{rpm}$. The magnitude of induced voltage produced from PM only is around $26.5 \mathrm{~V}$, with a certain distortion in the sinusoidal waveform as shown in Figure 4. Nevertheless, "FE only" generates lesser induced voltage than PM, although there is some distortion in the waveform. Although the magnitude of induced EMF is increased to nearly $35 \mathrm{~V}$ by combining both sources (PM and FE) due to field-strengthening effect. Whereas, it can be seen in the figure that the variation has also been decreased and validates that the suggested DS HEFSM motor operates seamlessly under safe region.

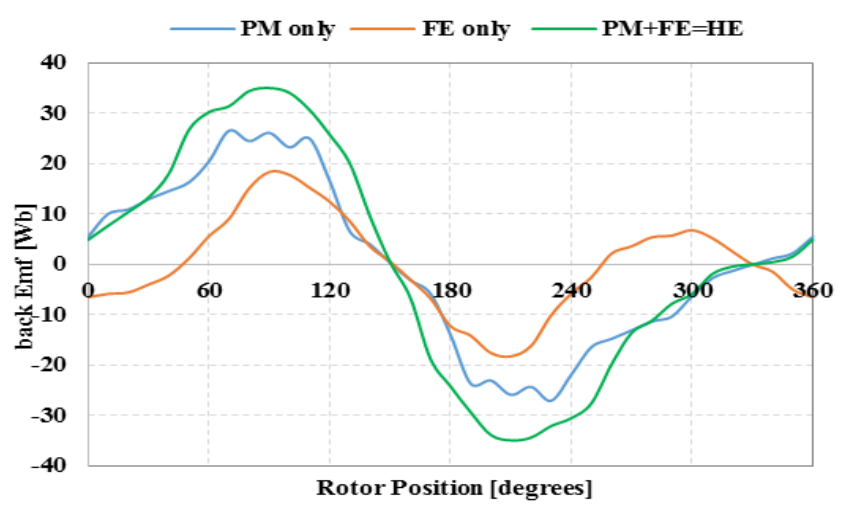

Figure 4. Induced EMF against rotor position

\subsection{Flux distribution and flux density at full load}

Magnetic flux distribution and flux density of suggested "DS HE-FSM" are examined at full load conditions for sources of excitations. The flux distribution of proposed "DS HE-FSM" are shown in Figure 5. Figure 5(a) displays the flux distribution at "field current density of $15 \mathrm{~A} / \mathrm{mm}^{2}$ " besides "armature current 
density of $15 \mathrm{Arms} / \mathrm{mm}^{2}$ ". It can be seen from figure that flux density at full load is $2.53 \mathrm{~T}$, whereas, above 2.53T, flux get saturated which can be seen at the tips of the teeth of outer stator in red circles. Besides, Figure 5(b) demonstrates the flux distribution" when "PM only" excitation is utilized at full load, realizing smooth distribution around the cores of machine and achieving the "maximum flux density of $2.60 \mathrm{~T}$ ". Whereas in case of Figure 5(c), in which "PM and FE" excitations are united to produce magnetic flux linkage. From Figure 5(c), the overall magnetic flux can be seen circulated almost $100 \%$ over the core of machine, due to the PMs, which are positioned on the surface of inner stator whereas around the outer stator almost $90 \%$ of "magnetic flux" is dispersed with $10 \%$ empty core caused by flux saturation at the tips of stator tooth and occurrence of leakage. Furthermore, from Figure 5(c), it is obvious that maximum and minimum flux density attained in "DS HE-FSM" are 2.9 T and 3.6 E-05 T respectively. This investigation affirms that the "DS HEFSM" competence enough to create high levels of flux densities to reach highest essential torque for aircraft applications at various speed ranges.

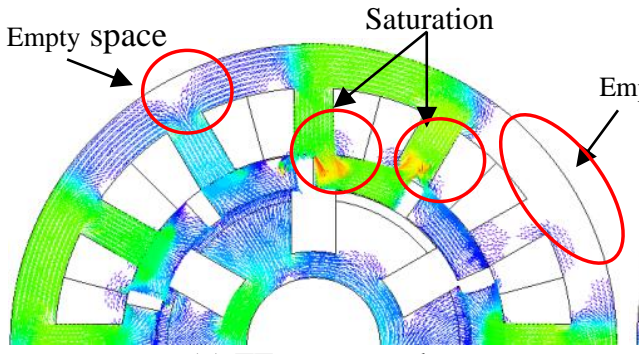

(a) FE source only

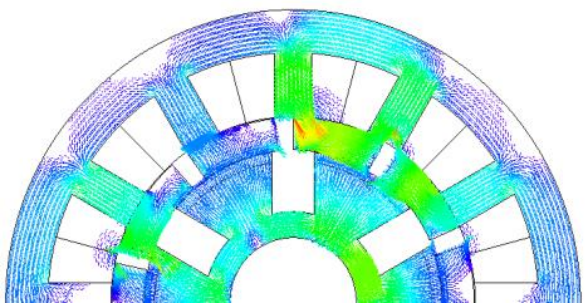

(c) Both sources (HE)

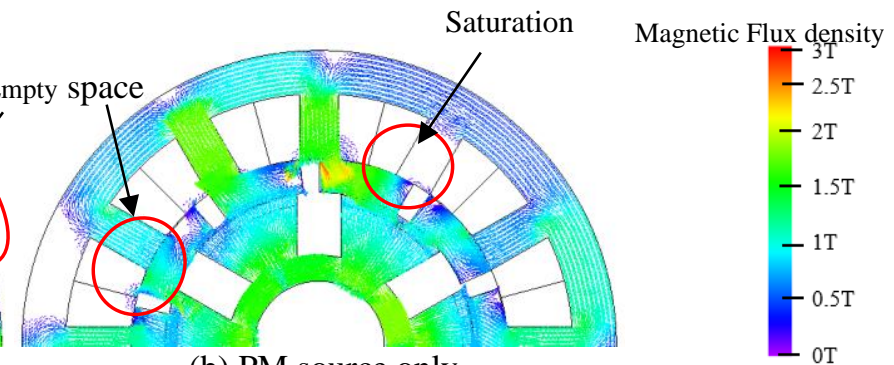

(b) PM source only

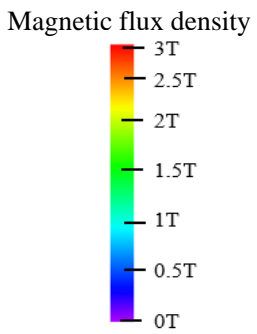

Figure 5. Magnetic flux density at different excitation sources

\section{TORQUE INVESTIGATION AT DIFFERENT CURRENT DENSITIES}

The torque investigation of proposed DS HE-FSM is conducted by inserting variable values of armature current densities from $3 \mathrm{Arms} / \mathrm{mm}^{2}$ to $15 \mathrm{Arms} / \mathrm{mm}^{2}$ at various loads. Henceforward, at maximum field current density of $15 \mathrm{~A} / \mathrm{mm}^{2}$, the value of torque has been observed at various "armature current densities $\left(J_{a}\right)$ " such as at $3 \mathrm{Arms} / \mathrm{mm}^{2}, 6 \mathrm{Arms} / \mathrm{mm}^{2}, 9 \mathrm{Arms} / \mathrm{mm}^{2}, 12 \mathrm{Arms} / \mathrm{mm}^{2}$ and $15 \mathrm{Arms} / \mathrm{mm}^{2}$. As a source of flux, PM produces consistent flux and thus the current density of the field is varied to evaluate the output torque at various loads. Figure 6 demonstrates the result of torque at various current densities under various currents in the armature. As from figure, it is shown that as the field current density raises, the amount of torque grows. Therefore, the flux generated from "PMs and FECs" is appropriately combined at high densities. This favors that the machine being proposed is able to generate higher torque at full load. From figure it seems to be clear that at a maximum "armature current density of $15 \mathrm{Arms} / \mathrm{mm}^{2}$ ", the maximum torque attained is about $160 \mathrm{Nm}$. In addition, the torque plot suggests that DS HE-FSM still tends to withstand the more fluxes while avoiding any saturation and cancellations between "PM and FEC" fluxes as shown in Figure 7. Electric motors for aircraft applications require high torques, especially at lower altitudes and lower speeds, hence, performances of DS HE-FSM are prominent to be applied for such applications. 


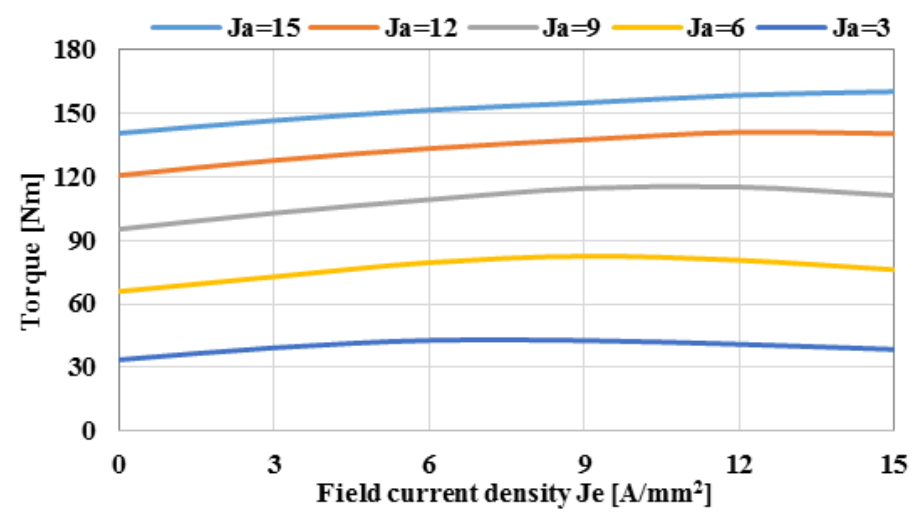

Figure 6. Average torque of DS HE-FSM with segmented rotor

\section{TORQUE AND POWER CHARACTERISTICS WITH RESPECT TO SPEED OF INITIAL DESIGN}

Figure 7 demonstrates the torque and power characteristics of the "DS HESFM". From figure, the graph of torque and power of the proposed design is presented in blue and orange lines respectively. Where, it is obvious from the figure that proposed "DS HE-FSM" has attained the maximum torque almost $160 \mathrm{Nm}$ which is continued till the base speed of $3750 \mathrm{rpm}$. Besides, the value of torque performance is reduced gradually and reaches till $10 \mathrm{Nm}$ at speed of around $16,000 \mathrm{rpm}$.

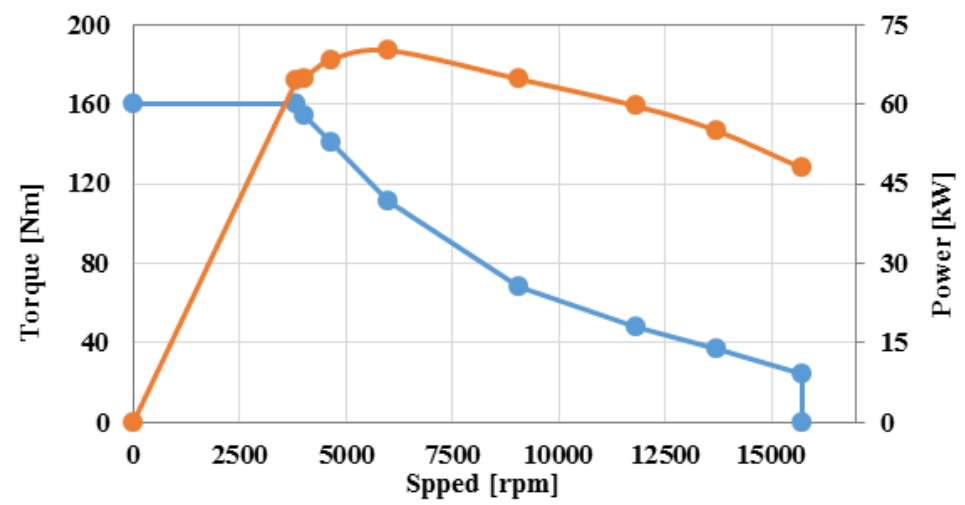

Figure 7. Torque and power vs speed chrachteristics of DS HE-FSM

Moreover, the initial design has attained maximum power of around $70 \mathrm{~kW}$ at speed of $6000 \mathrm{rpm}$. Nevertheless, with rise of speed, the value of power is slowly reduced until $48 \mathrm{~kW}$ at maximum speed. This slowly reduction in power is due to core and eddy current losses on the outer stator. As a conclusion, the proposed design of "DS HE-FSM" has realized adequate outcomes of maximum torque at high speed ranges. It also confirms that proposed "DS HE-FSM" can be the favorite solution for aircraft applications where high torque at high speeds is essential requirement.

\section{CONCLUSION}

This paper presents the design analysis and examination of DS HE-FSM. The investigated design includes two stators within a segmental rotor. Using JMAG designer, performance evaluation of presented design is examined based on 2D-FEA. The preliminary results of proposed design determines that the design has produced acceptable values of flux output, smoother flux lines and high torque output. In addition to this, back EMF, cogging torque, and flux distribution and flux lines have also been tested and confirmed that the proposed machine would work on safe mood with satisfactory outcomes. The expected study of magnetic flux and torque demonstrated that the suggested "DS HE-FSM" does have the potential to be further enhanced that can be used for various applications in the aircraft. 


\section{ACKNOWLEDGEMENTS}

This research work is sponsored by "Research and Management center" University Tun Hussein Onn Malaysia (UTHM), under research fund E15501.

\section{REFERENCES}

[1] C. Wenping et al., "Overview of Electric Motor Technologies Used for More Electric Aircraft (MEA)," IEEE Transactions on Industrial Electronics, vol. 59, no. 9, pp. 3523-3531, 2012.

[2] S. N. Motapon et al., "A comparative study of energy management schemes for a fuel-cell hybrid emergency power system of more-electric aircraft," IEEE Transactions on Industrial Electronics, vol. 61, no. 3, pp. 1320-1334, 2014.

[3] A. Boglietti et al., "The safety critical electric machines and drives in the more electric aircraft: A survey," 35th Annual Conference of IEEE Industrial Electronics, Porto, Portugal, 2009, pp. 2587-2594.

[4] B. K. Bose, "Power electronics and motor drives-Recent progress and perspective," IEEE Transactions on Industrial Electronics, vol. 56, no. 2, pp. 581-588, Feb. 2009.

[5] A. C. Hoffman et al., "Advanced Secondary Power System for Transport Aircraft," Washington, DC: NASA, May 1985, ser. NASA Technical Paper 2463.

[6] G. J. Atkinson et al., "The analysis of losses in high-power fault-tolerant machines for aerospace applications," IEEE Transactions on Industrial Applications, vol. 42, no. 5, pp. 1162-1170, 2006.

[7] B. K. Bose, "Power electronics and motor drives recent progress and perspective," IEEE Transactions on Industrial Electronics, vol. 56, no. 2, pp. 581-588, Feb. 2009.

[8] S. Dwari and L. Parsa, "Fault-tolerant control of five-phase permanentmagnet motors with trapezoidal back EMF," IEEE Transactions on Industrial Electronics, vol. 58, no. 2, pp. 476-485, Feb. 2011.

[9] E. Levi, "Multiphase electric machines for variable-speed applications," Transactions on Industrial Electronics, vol. 55, no. 5, pp. 1893-1909, May. 2008

[10] N. Bianchi and S. Bolognani, "Fault-tolerant PM motors in automotive applications," in Proc. IEEE Conference. Vehicle Power Propulsion, 2005, pp. 747-755.

[11] R. Krishnan and A. S. Bharadwaj, "A comparative study of various motor drive systems for aircraft applications," in Conference Record of the 1991 IEEE Industry Applications Society Annual Meeting, Dearborn, MI, 1991, vol. 1, pp. 252-258.

[12] T. Raminosoa and C. Gerada, "A comparative study of permanent magnet-synchronous and permanent magnet-flux switching machines for fault tolerant drive systems," in IEEE Energy Conversion Congress and Exposition (ECCE), 2010, pp. 2471-2478.

[13] T. Raminosoa et al., "Design Considerations for a Fault-Tolerant Flux-Switching Permanent-Magnet Machine," IEEE Transactions on Industrial Electronics, vol. 58, pp. 2818-2825, 2011.

[14] A. L. Shuraiji and M. M. J. Al-ani, "Design and optimization of HTS flux-switching permanent magnet machine," International Journal of Power Electronics and Drive System (IJPEDS), vol. 10, no. 4, pp. 1751-1757, Dec. 2019.

[15] Sulaiman et al., "A New Structure of 12Slot-10Pole Field-Excitation Flux Switching Synchronous Machine for Hybrid Electric Vehicles," Proceedings of 14th European Conferences on Power Electronics and Applied. (EPE), UK, Paper No. 362, 2011

[16] Soomro et al., "Performance Comparison and analysis of (HE-FSM) and (FEFSM) using Segmental rotor Structure," Applied Mechanics and Materials, vol. 695, pp. 778-782, 2015

[17] E. I. Mbadiwe et al., "Permanent magnet flux switching motor technology as a solution for high torque clean electric vehicle drive," International Journal of Power Electronics and Drive System (IJPEDS), vol. 10, no. 2, pp. 575-584, Jun. 2019.

[18] C. Sanabria-Walter et al., "High-Torque Density High-Efficiency Flux-Switching PM Machine for Aerospace Applications," IEEE Journal of Emerging and Selected Topics in Power Electronics, vol. 1, no. 4, pp. 327-336, Aug. 2013.

[19] I. Boldea et al., "Automotive electric propulsion systems with reduced or no permanent magnets: An overview," IEEE Transactions on Industrial Electronics, vol. 61, no. 10, pp. 5696-5711, Oct. 2014.

[20] Z. Q. Zhu et al., "A Wound Field Switched Flux Machine with Field and Armature Windings Separately Wound in Double Stators," IEEE Transactions on Energy Conversion, vol. 30, no. 2, pp. 772-783, Jun. 2015.

[21] F. Amin et al., "Modelling and Simulation of Field Oriented Control based Permanent Magnet Synchronous Motor Drive System," Indonesian Journal of Electrical Engineering and Computer Science, vol. 6, no. 2, pp. 387-395, May. 2017.

[22] M. F. Omar et al., "Optimal Design of Single-phase 12S-6P FEFSM Using Segmental Rotor and Non-Overlap Windings," Indonesian Journal of Electrical Engineering and Computer Science, vol. 14, no. 2, pp. 735-743, 2019.

[23] H. Ali et al., "Design and performance analysis of various high torque segmented rotor HE-FSM topologies for aircraft applications," in IET Electric Power Applications, vol. 14, no. 2, pp. 297-304, 2020.

[24] F. Capponi et al., "Flux regulation hstrategies for hybrid excitation synchronous machines," IEEE Transactions on Industrial Appliations, vol. 51, no. 5, pp. 3838-3847, 2015.

[25] Y. Amara et al., "Hybrid excitation synchronous machines: energy-efficient solution for vehicles propulsion," IEEE Transactions on Vehicular Technology, vol. 58, no. 5, pp. 2137-2149, Jun. 2009 


\section{BIOGRAPHIES OF AUTHORS}
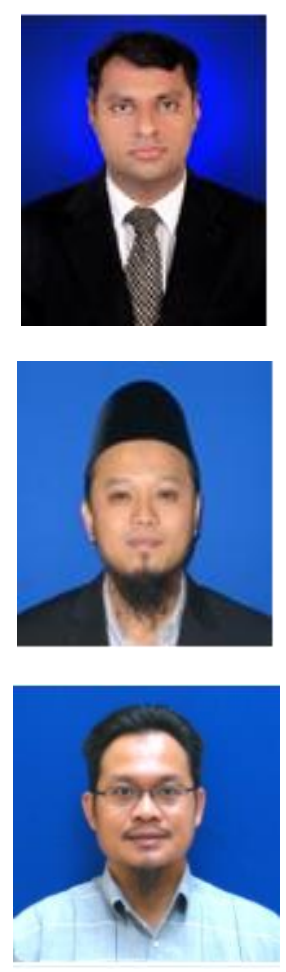

Mahyuzie Jenal got his birth in Johor, Malaysia, on December 4, 1977. He got his B.E and M.E degrees in Electrical Engineering from Universiti Teknologi Malaysia in 2000 and Universiti Tun Hussein Onn Malaysia (UTHM) in 2009. He has completed his $\mathrm{PhD}$ from Universiti Tun Hussein Onn Malaysia (UTHM) in 2020. He has been with UTHM from June 2003 as instructor and selected as a lecturer in 2009. His research interest is electric machine design especially in permanent magnet flux switching machine.
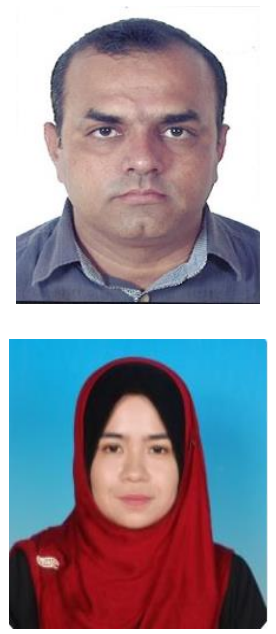

Irfan Ali Soomro is a researcher. He received bachelor's degree in Electrical Engineering from Quaid-e-Awam University of Engineering, Science and Technology, Nawabshah Sindh, Pakistan. Currently he is a full-time researcher at Universiti Tun Hussein Onn Malaysia (UTHM). Currently, he is pursuing his research in electrical power engineering at the same university consecutively. His research interest includes design of flux switching motor.

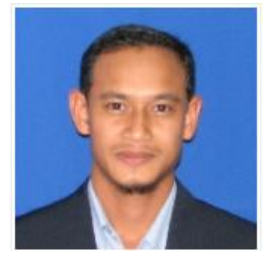

Mohd Zarafi Bin Ahmad received his BE degree in electrical engineering from University Technology Mara in 2003 and ME degree in electrical engineering from University Technology Malaysia in 2006. He has been a lecturer at University Tun Hussein Onn Malaysia since 2006 where he received his $\mathrm{Ph} . \mathrm{D}$ in 2017. His research interests include electric machine design and drive control.

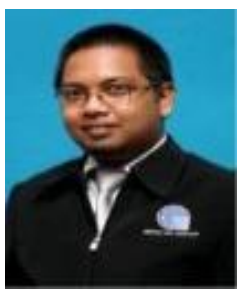

Mohd Firdaus Mohd Ab Halim graduated from Universiti Tenaga Nasional in Bachelor of Electrical Engineering. He finished Master Degree of EEIT at University of Applied Science Rosenheim, Germany. Currently he is a full-time researcher at Universiti Teknikal Malaysia Melaka, Fakulti Teknologi Kejuruteraan. His reseach mainly focus in Energy Efficiency, Renewable Energy and Electrical Vehicle. Currently he is full time studying Doctor Of Philosophy In Electrical Engineering in Universiti Tun Hussein Onn (UTHM) 